\title{
STATIC ANALYSIS of a SINGLE STAGE HYDRAULIC CYLINDER.
}

\author{
V.GómezRodríguez ${ }^{\# 1}$,Juan José CabelloEras ${ }^{\# 2}$,Hernán HernándezHerrera ${ }^{\# 3}$,Rafael \\ GoytisoloEspinosa $^{\# 4}$. \\ ${ }^{\# 1}$ Bolivariano Technological Institute of Technology. Guayaquil. Ecuador. \\ 1vgomez@bolivariano.edu.ec \\ ${ }^{\# 2}$ Faculty of Engineering, Universidad de la Costa.Barranquilla, Colombia. \\ ${ }_{2}$ jcabel1o2@cuc.edu.co \\ ${ }^{\# 3}$ Faculty of Engineering, Universidad de la Costa.Barranquilla, Colombia. \\ hhernand16@cuc.edu.co \\ ${ }^{\# 4}$ Faculty of Engineering, Universidad de Cienfuegos. Cienfuegos, Cuba. \\ ${ }^{4}$ ragoyti@ucf.edu.cu
}

\begin{abstract}
In this study the static analysis of a single stage hydraulic cylinder is considered. A complete theoretical model is developed that allows the consideration of all the factors that affect the statics of a hydraulic cylinder in its action as a compression member. The scheme is based on the classical EulerBernoulli beam theory, and makes detailed account of all the loadings present, and of the various types of boundary conditions.
\end{abstract}

Keywords-Scheme of analysis, Hydraulic cylinder, Single stage, New factors

\section{INTRODUCTION}

Hydraulic cylinders are compression members consistingof parts having different rigidity. In the simplest casethere are two parts (Fig. 1), but in more complicated cases,such as telescopic cylinders, there are several parts [1],[2], [3]. Anumber of different combinations of support conditions atthe ends are encountered in these problems. In the simplestcase there are pinned supports at both ends, while in othercases the supports may be pinned-fixed, doubly-fixed, orfixed-free. In exceptional conditions, hydraulic cylindersoperate solely in the vertical condition, but morecommonly they operate in an inclined position or in acompletely horizontal position. In these latter positions theself-weight of the cylinder and the hydraulic fluid oftenprovide a transverse load that increases the eccentricity ofaxial loads. Further factors requiring consideration are thesliding joint between the rod and cylinder, and thelooseness in the joints, implying elasticity in theconnections or supports. The components forming thehydraulic cylinder have step-variations in their stiffness, and thus the equation governing the deflection isdiscontinuous over the domain, which complicates theanalysis.

In the technical literature a number of approaches for theanalysis of compression members have been presented [4[, [5], [6], [7], but none has completely addressed the full details thatare encountered with practical hydraulic cylinders. Articles and thestudy of the various catalogs provided by suppliers ofhydraulic cylinders indicate that some details related tohydraulic cylinders are not taken into consideration, andthat approximate approaches of analysis are applied, whichmay in cases lead to non-conservative results [8], [9], [10]. The industry produces a variety of hydraulic cylinderproducts, and generally carries out complete designs for itsproducts. Nevertheless, there is no available methodology,appropriate for comprehensive analysis of hydrauliccylinders, which accounts for both transverse and axialloads. Thus a comprehensive scheme of calculation isrequired which considers completely the various loadingand support conditions that may arise, and whichultimately leads to a safe product having economicaldimensions.

\section{A. Stability analysis of compression members.}

The classical method of stability analysis of a compressionmember is described by Timoshenko [11]. Other methodsexist which offer a more detailed consideration of theproblem [12], [13], [14]. These methods include the classical Euler-Bernoullimethod based on an approximate differentialequation for the elastic bending of a beam, methods basedon semi-empirical formulas, the method of the $\varphi$-coefficient for the reduction of the admissible stress, energymethods, the method of the parameters of the origin, themethod of the integration of the differential equation, thefinite element method, the secant formula for the case ofcolumns with eccentric load, and the method of limit loadsfor the case of the loss of stability due to simultaneouslongitudinal and transverse bending. Most of thesemethods cover only compression members having constantrigidity, and thus cannot be applied directly to hydrauliccylinders. It has been shown that the method of parametersof the origin to determine the critical load, whilepermitting the analysis of structures with variable rigidity,is excessively complicated in solution if all the factorsaffecting the problem are to be considered [15]. 


\section{B. Static analysis of hydraulic cylinders.}

With the development of computer-aided methods, and theavailability of new mathematical approaches, attemptshave been made to overcome difficulties posed byequations governing domains containing stepvariations inproperties [16],[17]. The model proposed by [15] considered the cylinder as a beam with step variationsin rigidity, subjected to perfect loading (no eccentricities),and lacking of initial curvature. In this approach thepossible influence of a loose fit in the joints is notconsidered, nor the effect of self-weight in the case whenthe cylinder adopts a position at an angle to the vertical.

In paper [18] analyzed the influence of the extension length on loads distribution through sliding contacts along the boom. In another work [19], a method is used which permitsdetermination of stability characteristics for cylinder of anynumber of stages. The results obtained in that work aresuperior to results obtained in other works. A deficiency inprevious methods stems from the fact that the self-weightof the cylinder is not considered, despite the fact that it hasa substantial influence on the deformation of the rod in anarticulated system. The influence is due to the bendingcaused by the self-weight, and to the moment causing asagging equal only to the deformation produced by theloose fit of the sliding joint in each stage. In other work[20] the bending is determined without considering that therod is subjected to a combination of transverse andlongitudinal flexure. In further studies empirical methodshave also been presented to determine the stability ofhydraulic cylinders, and the finite element method hasbeen used, in which the cylinder is modeled as a columnwith a cross-section that varies in the longitudinaldirection.

\section{THEORY.}

C. Modeling of the system

In the scheme of analysis presented in this study thefollowing factors are taken into account, which generallyhave not been considered in previous studies:

- Loose fit existing between the piston - body androd - and the axle box.

- Self-weight of the cylinder and the hydraulicfluid.

- Moment caused by the friction in pinned joints.

- A general treatment of the supports: fixed,pinned, elastic, etc.

- Positioning of a support along the length of thecylinder.

- Inclination of the cylinder.

- Eccentricity of the axial load at either end.

- Variation in the slope produced by the elasticity ofthe axle box and seals.

- The details of the construction of the rod: solid orhollow, with or without internal pressure.

D. Scheme of the analysis.

The scheme of analysis proposed for a cylinder of singlestage is shown in Figs. 1a and 1b.

Where:

$\mathrm{W}_{\text {CULATA }}, \mathrm{L}_{\text {CULATA }}$ - weight and length of the cylinder head.

$\mathrm{W}_{\mathrm{LH}}, \mathrm{L}_{\mathrm{CP}}$ - weight of the hydraulic fluid and length of fluidcolumn from the head to the front face of the piston.

$\mathrm{W}_{\mathrm{C}}, \mathrm{L}_{\mathrm{C}}-$ weight and length of the cylindrical tube.

$\mathrm{Wv}, \mathrm{Lv}$ - weight and length of the rod.

Wcp, Wbg, Wtu - weight of the head of the piston, theguiding axle and the bolts of the attachment.

$\mathrm{W}_{\mathrm{OREJA}}, \mathrm{L}_{\mathrm{OREJA}}$ - weight and length of the ring connection.

$\mathrm{Lp}$ - distance from the head to the intermediate support.

It is considered that the two components of the model, CAand CB (Fig. 1b), have a rigidity equal to that of acylindrical tube (sleeve) $R_{1}$ and that of a rod, respectively $R_{2}$. Thecomponents are subject to a uniformly distributed loadingequal to the combined sum of the various components andthe hydraulic fluid, divided by the length. The transitionpoint $\mathrm{C}$ is the point where the axis of the cylindrical tubeand the axis of the rod intersect, when the system deformsdue to the action of applied loads. The weight $\mathrm{W}$ of thesliding connection between the cylindrical body and therod is considered as a load concentrated at the transitionpoint $\mathrm{C}$, as indicated in Fig. 1b. The weights of the axlebox and the piston head are included in the concentratedload $\mathrm{W}$ acting at the transition point C. 


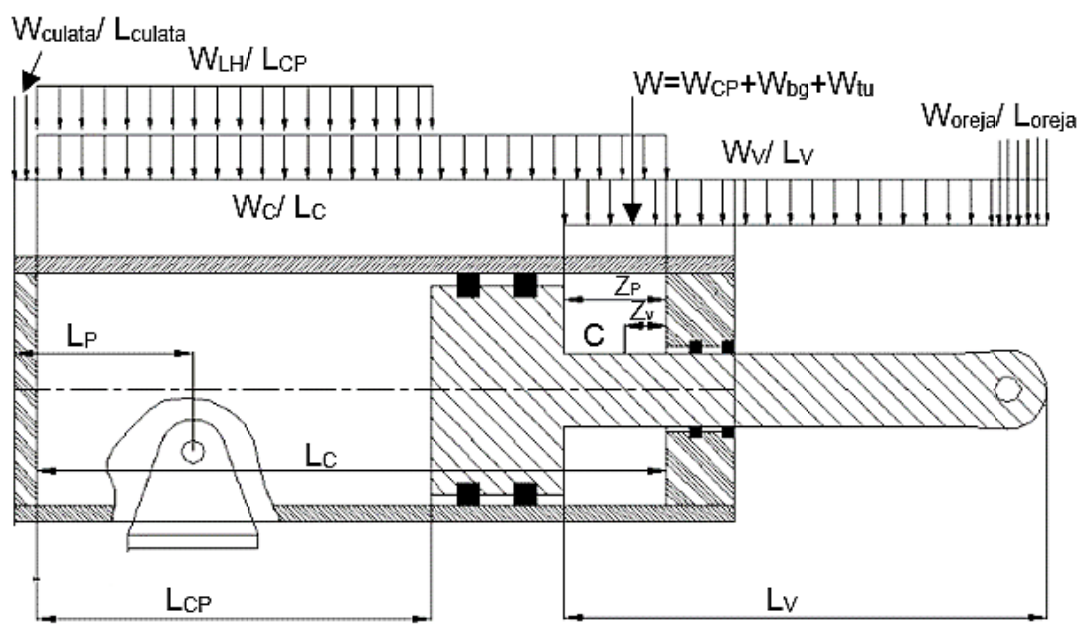

Fig. 1a. System of loads for a practical hydraulic cylinder.

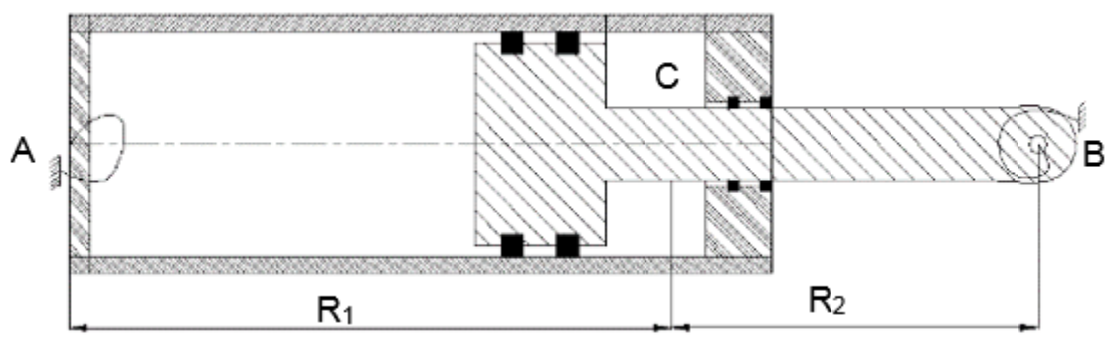

Fig. 1b.Rigidity of the two components.

In Fig. 2 there ispresented justification for the consideration of thesedistributed loads as a concentrated load at point $\mathrm{C}$, where itis clear that the difference caused in the flexural moment issmall.
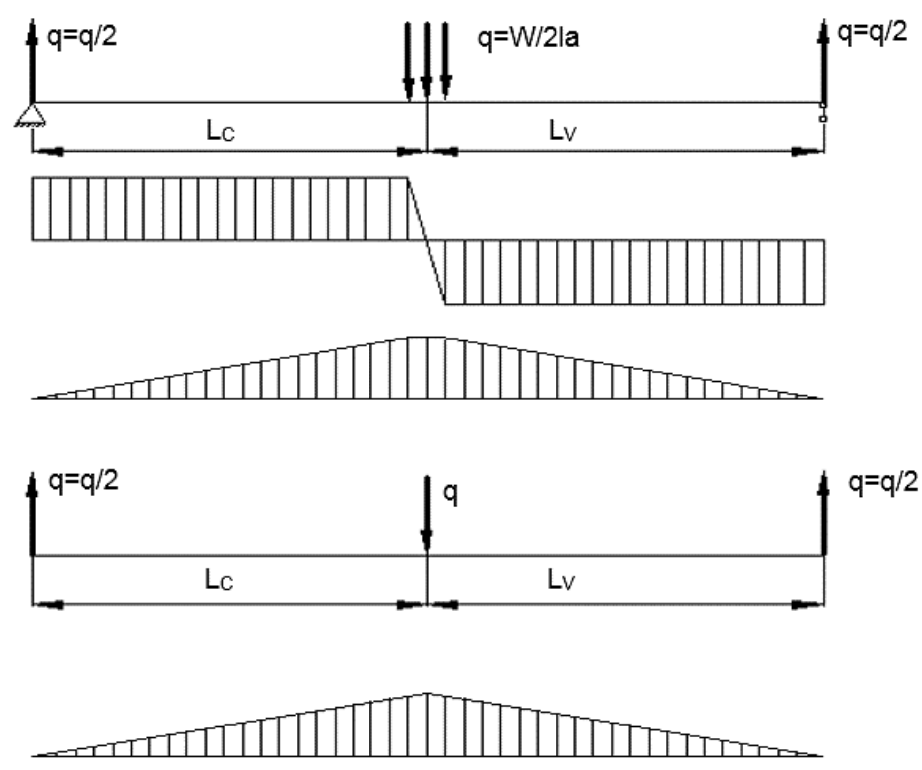

Fig. 2. Comparison of moments for idealizations of the load at point $\mathrm{C}$.

The moment with respect to point $\mathrm{C}$, produced by the weight of the piston head, the axle box, and the supported parts distributed due to the weight of the cylinder and the rod were not considered due to their negligible effect see Fig. 3. For the case of a cylinder with an intermediate support, the moment produced by the weight of the cantilever part was applied at the position of support of the cylinder. The axle box and the seal were considered as elastic elements, and replaced by linear springs. 

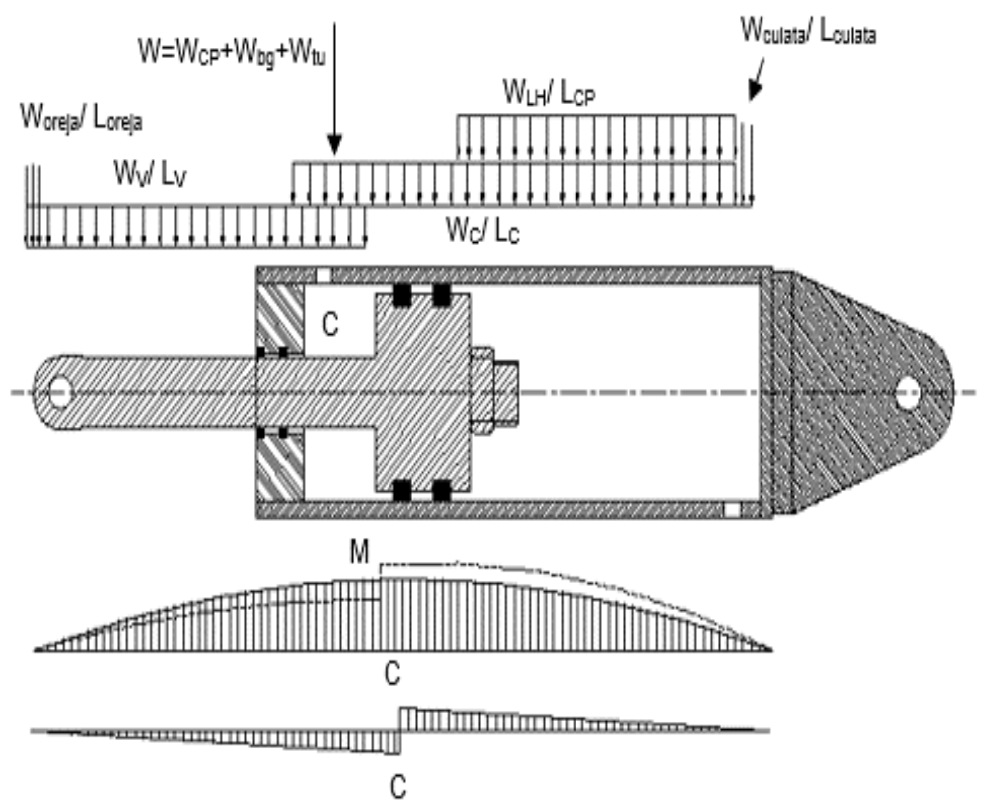

Fig. 3. Symbolic plot representing the effect of the moment M produced by the concentrated load $\mathrm{W}$ at point $\mathrm{C}$.

\section{E. Details of the static analysis of a single stage cylinder.}

Expressions may be written for the moment, slope, and displacement valid at every point along the length of the cylinder. In Fig. 4 is shown the configuration of a single stage cylinder, including the applied forces and reactions. In this diagram:

$\mathrm{P}-$ axial load on the cylinder.

$\mathrm{L}-$ length between supports of the cylinder.

ec, ev - eccentricities of the axial load in the cylinder androd.

$\beta c, \beta v$ - angular deviations of the axis of the cylinder andthe axis of the rod with respect to the supports.

$\mathrm{kc}, \mathrm{kv}-$ stiffnesses of the rotational springs in the pins ofthe supports of the cylinder and rodrespectively (angular rigidity of the supports).

$f_{c}, f_{v}$ - coefficients of friction in the pins of the supportsof the cylinder and rod respectively.

$\mathrm{R}_{\mathrm{c}}$ - lateral reaction of the support of the cylinderproduced by the self-weight of the system.

$\mathrm{R}_{\mathrm{v}}$ - lateral reaction of the support of the rod produced bythe self-weight of the system.

$M p=\frac{W_{I} \cdot I_{2}^{P}}{2}$ moment produced by the self-eightof thecantilever part of the body

$\mathrm{W}$ - concentrated force at point $\mathrm{C}$ due to the weight of thepiston, the axle box, and of the parts of the cylinderand the rod in the sliding joint.

$\mathrm{w}_{1}$-weight per unit length of the cylinder and thehydraulic fluid.

$\mathrm{w}_{2}$-weight per unit length of the rod.

In Fig. 4 are shown the reactions produced by the difference in eccentricities between the support of the rod and the support of the body, the reaction produced by the moment of friction in the pinned joints, the reaction produced due to the rigidity in rotation of the fixed ends, and the reactions produced by the self-weight of the system: the reaction produced by the cantilever part of the cylinder in cases containing intermediate supports, the reaction produced by the weight of the cylinder tube, the rod and the hydraulic fluid, and the reaction produced by the concentrated force at the point $\mathrm{C}$. 

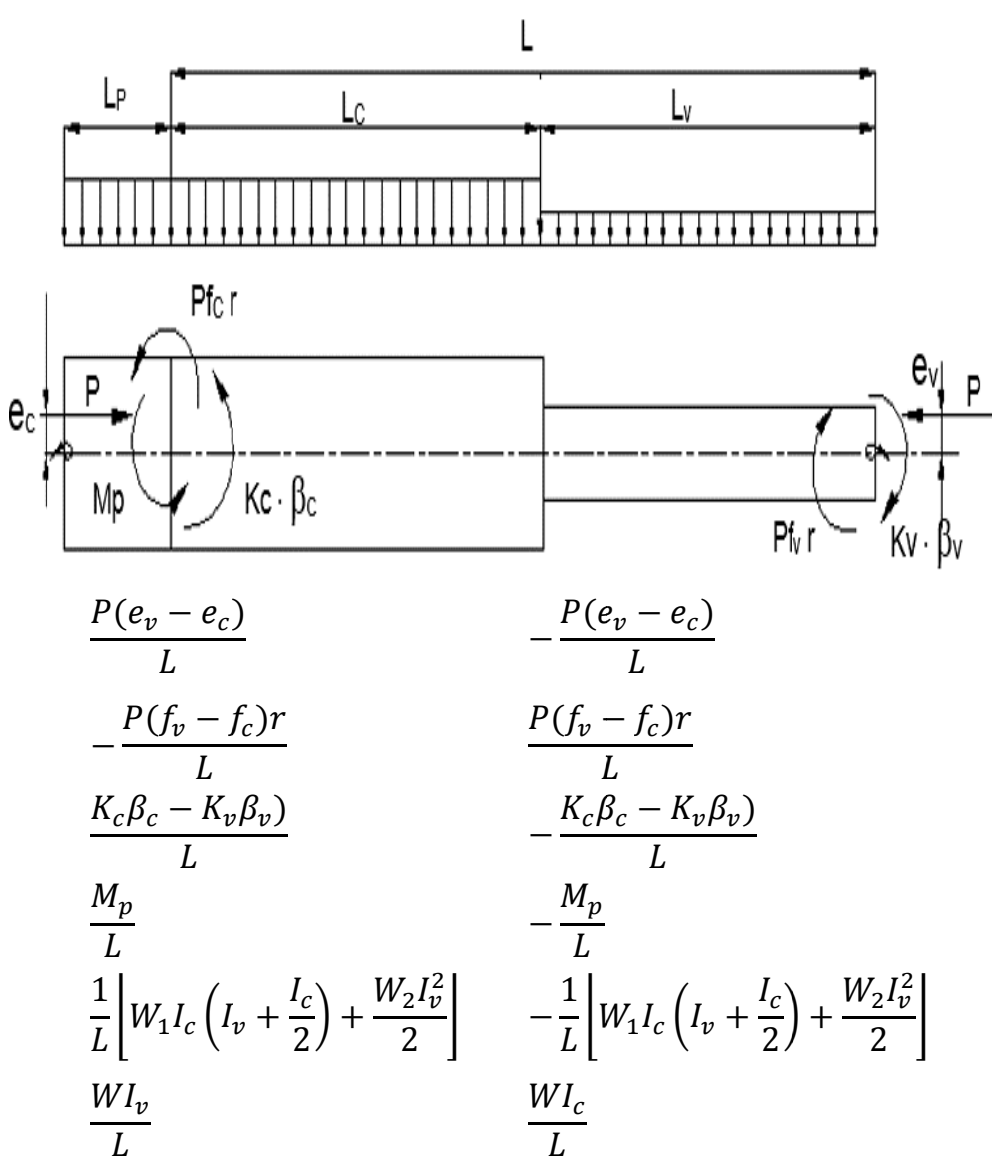

Fig. 4. External forces and reactions in a single stagehydraulic cylinder.

In this analysis, the differential equations for the deflection are written for the tube and rod parts of the hydraulic cylinder. These differential equations are enforced together with the boundary conditions, and the conditions of compatibility to obtain the equations governing the bending of the member. The geometric details for a single stage hydraulic cylinder, in three possible positions, are shown in Fig. 5: completelystraight, with an initial slope $\beta$ ' but without any axial load, and with a slope of $\beta$ which increases with an increase in the load. The system passes through these three states when it is subject to an axial load at the end. It is clear that the angular deviation at any point of the system is, from one part, owing to the presence of the slope, and from the other part, owing to the flexure of the body of the tube and the rod.

In Fig. 5 the portion of the deviation from the absolute straight position to the position indicated by the dotted lines is due to the slope, and the portion of the dotted lines in the deformed position is due to the flexural moment of the system. The differential equations are written for the overall effect.
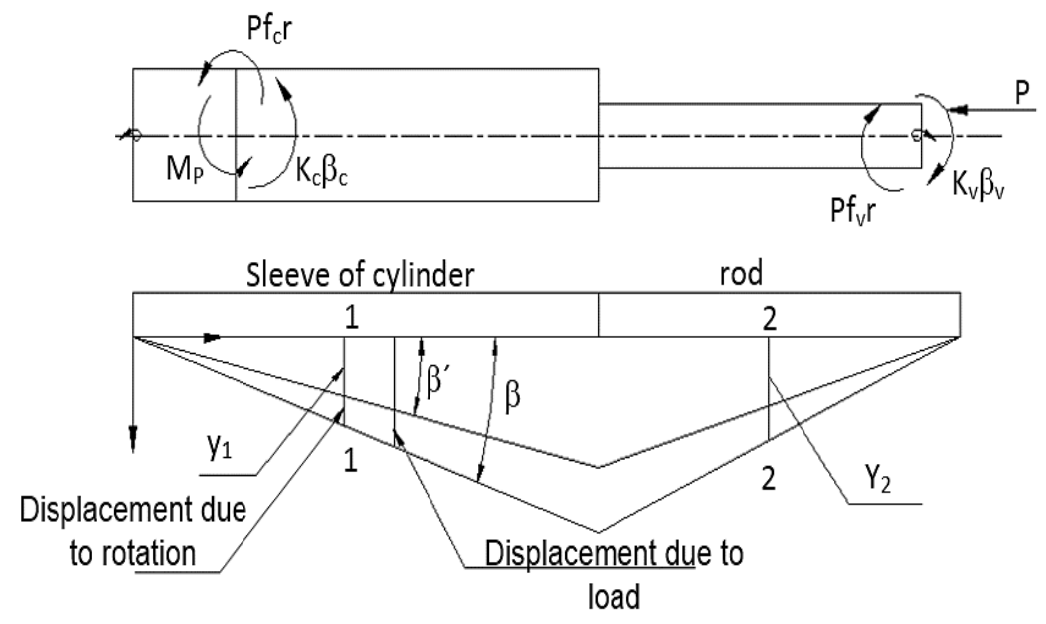

Fig. 5. Tangent displacement lines in a typical hydraulic cylinder 


\section{EQUATIONS FOR THE CALCULATION SCHEME.}

For an arbitrary section of the tube part, for example the section 1-1 of Fig. 5, the flexural moment that produces the curvature is obtained by taking the product of the flexural rigidity with the second derivative of the displacement for this part, namely:

$$
M_{1}=-E_{1} \cdot I_{1} \frac{d^{2} \cdot y_{1}}{d z^{2}}
$$

The flexural moment in this section produced by theexternal loads and the reactions is:

$M_{1}=\frac{P\left(e_{v}-e_{c}\right)}{L} z-\frac{P\left(f_{v}-f_{c}\right)}{L} z+\frac{\left(k_{c} \beta_{c}-k_{v} \beta_{v}\right)}{L}+R_{c} z-M_{p}-P \cdot f_{c}-k_{c} \cdot \beta_{c}-\frac{w_{1}}{2} z^{2}$

$+P\left(e_{c}+y_{1}\right)$

Where:

$\mathrm{y}_{1}$ - displacement at a distance $\mathrm{z}$ in the cylinder,measuredwith respect to the left support.

For equilibrium the internal and external moments must beequal. Thus combining equations (1) and (2) one obtains.

$\frac{d^{2} y_{1}}{d z^{2}}+k_{1}^{2} y_{1}=k_{1}^{2}\left[-\frac{\left(e_{v}-e_{c}\right)}{L} z+\frac{\left(f_{v}-f_{c}\right)}{L} z-\frac{\left(k_{c} \beta_{c}-k_{v} \beta_{v}\right)}{P L} z-\frac{R_{c}}{P} z+\frac{M_{p}}{P}+f_{c}+\frac{k_{c} \beta_{c}}{L}-e_{c}+\frac{w_{1}}{2 P} z^{2}\right\rceil$

Where:

$K_{1}^{2}=\frac{P}{E_{1} I_{1}}$

An analysis is next carried for the rod part of thestructural member (section 2-2, Fig. 5), for which one obtains:

$\frac{d^{2} y_{2}}{d z^{2}}+k_{2}^{2} y_{2}=k_{2}^{2}\left[-\frac{\left(e_{v}-e_{c}\right)}{L}(L-z)+\frac{\left(f_{v}-f_{c}\right)}{L}(L-z)-\frac{\left(k_{c} \beta_{c}-k_{v} \beta_{v}\right)}{P L}(L-z)-\frac{R_{v}}{P}(L-z)\right.$

$\left.+f_{v}+\frac{k_{v} \beta_{v}}{P}-e_{v}+\frac{w_{2}}{2 P}(L-z)^{2}\right]$

Where:

$K_{2}^{2}=\frac{P}{E_{2} I_{2}}$

The differential equations (3) and (4) describe thebehavior of the displacements in the tube and the rod parts of a hydraulic cylinder carrying an axial load.The boundary conditions, and the continuity conditions to be satisfied in solving these equations are:

$$
\begin{array}{cc}
z=0 & y_{1}=0 \\
z=L & y_{2}=0 \\
z=l_{c} & y_{1}=y_{2} \\
z=l_{c} & \frac{d y_{1}}{d z}-\beta=\frac{d y_{2}}{d z}
\end{array}
$$

The solution for equations (3) and (4) are obtainedas:

$$
\begin{aligned}
& y_{1}=C_{1} \cos \left(K_{1} \cdot z\right)+D_{1} \sin \left(K_{1} \cdot z\right)-\frac{\left(e_{v}-e_{c}\right)}{L} z+\frac{\left(f_{v}-f_{c}\right)}{L} z-\frac{\left(k_{c} \beta_{c}-k_{v} \beta_{v}\right)}{P L} z-\frac{R_{c}}{P} z+T_{1}+\frac{k_{c} \beta_{c}}{P} \\
&+ \frac{w_{1}}{2 P} z^{2} \\
&\left(0 \leq z \leq l_{c}\right.
\end{aligned}
$$

and

$$
\begin{aligned}
& y_{2}=C_{2} \cos \left(K_{2} \cdot z\right)+D_{2} \sin \left(K_{2} \cdot z\right)-\frac{\left(e_{v}-e_{c}\right)}{L}(L-z)+\frac{\left(f_{v}-f_{c}\right)}{L}(L-z)-\frac{\left(k_{c} \beta_{c}-k_{v} \beta_{v}\right)}{P L}(L-z) \\
& -\frac{R_{v}}{P}(L-z)+T_{2}+\frac{k_{v} \beta_{v}}{P}+\frac{w_{2}}{2 P}(L-z)^{2} \\
& \left(l_{c} \leq z \leq L\right.
\end{aligned}
$$

Where:

$T_{1}=\frac{M_{p}}{P}+f_{c}-e_{c}-\frac{W_{1}}{P K_{1}^{2}}$ 
$T_{2}=f_{v}-e_{v}-\frac{W_{2}}{P K_{2}^{2}}$

Where $\mathrm{C}_{1}, \mathrm{C}_{2}, \mathrm{D}_{1}$, and $\mathrm{D}_{2}$ are constants to bedetermined from the conditions (5).

Application of the equations (5) leads to the following values for the constants $\mathrm{C}_{1}$ and $\mathrm{C}_{2}$.

$C_{1}=-T_{1}-\frac{K_{c} \beta_{c}}{P}$

$C_{2}=\left[-D_{2} \sin \left(K_{2} L\right)-T_{2}-\frac{K_{v} \beta_{v}}{P}\right] \frac{1}{\cos \left(K_{2} L\right)}$

With the application of the continuity conditions at the sliding joint, i.e. at $\mathrm{z}=\mathrm{l}_{\mathrm{c}}$ and substituting the values of $\mathrm{C}_{1}$ and $\mathrm{C}_{2}$ from equations (10) and (11) one obtains therelation.

$D_{1} \sin \left(K_{1} I_{c}\right)+D_{2} \frac{\sin \left(K_{2} I_{v}\right)}{\cos \left(K_{2} L\right)}=\left[T_{1}+\frac{K_{c} \beta_{c}}{P}\right] \cos \left(K_{1} I_{c}\right)-\left[T_{2}+\frac{K_{v} \beta_{v}}{P}\right]\left[\frac{\cos \left(K_{2} I_{c}\right)}{\cos \left(K_{2} L\right)}\right]-T_{3}$

Where:

$T_{3}=\frac{W_{2}}{P K_{2}^{2}}-\frac{w_{1}}{P K_{1}^{2}}$

The equations for the slope are obtained as the first derivative of the displacements (6) and (7) as:

$\frac{d y_{1}}{d z}=-C_{1} K_{1} \sin \left(K_{1} \cdot z\right)+D_{1} K_{1} \cos \left(K_{1} \cdot z\right)-\frac{\left(e_{v}-e_{c}\right)}{L}+\frac{\left(f_{v}-f_{c}\right)}{L}-\frac{\left(k_{c} \beta_{c}-k_{v} \beta_{v}\right)}{P L}-\frac{R_{c}}{P}+\frac{w_{1}}{2 P} z$

$\left(0 \leq z \leq l_{c}\right.$

$\frac{d y_{2}}{d z}=-C_{2} K_{2} \sin \left(K_{2} \cdot z\right)+D_{2} K_{2} \cos \left(K_{2} \cdot z\right)-\frac{\left(e_{v}-e_{c}\right)}{L}+\frac{\left(f_{v}-f_{c}\right)}{L}-\frac{\left(k_{c} \beta_{c}-k_{v} \beta_{v}\right)}{P L}+\frac{R_{v}}{P}-\frac{w_{2}}{2 P}(L-z)$

$\left(l_{c} \leq z \leq L\right)$

Enforcing the continuity conditions at the slidingjoint, and substituting the values of $\mathrm{C}_{1}$ and $\mathrm{C}_{2}$ from equations (10) y (11), one obtains:

$D_{1} K_{1} \sin \left(K_{1} I_{c}\right)-D_{2} K_{2} \frac{\cos \left(K_{2} I_{v}\right)}{\cos \left(K_{2} L\right)}=\left(-T_{1}-\frac{K_{c} \beta_{c}}{P}\right) K_{1} \sin \left(K_{1} I_{c}\right)+\left[T_{2}+\frac{K_{v} \beta_{v}}{P}\right]\left[\frac{K_{2} \sin \left(K_{2} I_{c}\right)}{\cos \left(K_{2} L\right)}\right]+\frac{W}{P}$

$+\beta$

Where:

$W=R_{c}+R_{v}-w_{1} I_{c}-W_{2} I_{v}$

Solving simultaneously the equation (12) and (16) one obtains:

$D_{1}=\frac{1}{Q}\left\{\left[\frac{K_{c} \beta_{c}}{P}+T_{1}\right]\left[\frac{\left(K_{2}-K_{1} \tan \left(K_{1} I_{c}\right) \tan \left(K_{2} I_{v}\right)\right)}{\tan \left(K_{1} I_{c}\right) \operatorname{tang}\left(K_{2} I_{v}\right)}\right]-\left[T_{2}+\frac{K_{v} \beta_{v}}{P}\right]\left[\frac{K_{2}}{\sin \left(K_{1} I_{c}\right) \sin \left(K_{2} I_{v}\right)}\right]\right.$

$\left.-\frac{T_{3} K_{2}}{\sin \left(K_{1} I_{c}\right) \sin \left(K_{2} I_{v}\right)}+\left[\beta+\frac{W}{P}\right] \frac{1}{\sin \left(K_{1} I_{c}\right)}\right\}$

$D_{2}=\frac{1}{Q}\left\{\left[\frac{K_{c} \beta_{c}}{P}+T_{1}\right]\left[\frac{K_{1} \cos \left(K_{2} L\right)}{\sin \left(K_{1} I_{c}\right) \sin \left(K_{2} I_{v}\right)}\right]-\left[T_{2}+\frac{K_{v} \beta_{v}}{P}\right]\left[\frac{K_{2} \operatorname{tang}\left(K_{1} I_{c}\right) \operatorname{tang}\left(K_{2} I_{c}\right)+K_{1}}{\tan \left(K_{1} I_{c}\right) \sin \left(K_{2} I_{v}\right)}\right]\right.$

$\left.-\frac{T_{3} K_{1} \cos \left(K_{2} L\right)}{\tan \left(K_{1} I_{c}\right) \sin \left(K_{2} I_{v}\right)}-\left[\beta+\frac{W}{P}\right]\left[\frac{\cos \left(K_{2} L\right)}{\sin \left(K_{2} I_{v}\right)}\right]\right\}$

Where:

$Q=\frac{K_{1}}{\tan \left(K_{1} I_{c}\right)}+\frac{K_{2}}{\tan \left(K_{2} I_{v}\right)}$

The values of the constants $\mathrm{C}_{1}, \mathrm{C}_{2}, \mathrm{D}_{1}$ and $\mathrm{D}_{2}$ in the displacement equations (6) and (7) and the equations for the slope (14) and (15) are obtained from the relations (10), (11), (17) y (18), respectively.

The slope $\beta$ is evaluated using a procedure proposed by the authors. The other two unknown values, $\beta_{\mathrm{c}} \mathrm{y}$ $\beta_{\mathrm{v}}$ which appear in the equations of displacement and slope and in the equations to determine $C_{1}, C_{2}, D_{1}$ and $\mathrm{D}_{2}$ are found by enforcing the following conditions of compatibility.

$Z=0 \quad \frac{d y_{1}}{d z}=\beta_{c}$

And 
$Z=l \quad \frac{d y_{2}}{d z}=\beta_{v}$

On combining the equations (10), (11), (14), (15),(17),(18), and (20) one obtains two relations which have theform:

$\beta_{c} A_{I I}+\beta_{v} A_{12}=B_{1}$

And

$\beta_{c} A_{2 I}+\beta_{v} A_{22}=B_{2}$

Where:

$A_{I I}=1-\frac{K_{c}}{P} \frac{K_{1}\left(K_{2}-K_{1} \tan \left(K_{1} I_{c}\right) \tan \left(K_{2} I_{v}\right)\right)}{K_{1} \tan \left(K_{2} I_{v}\right)+K_{2} \tan \left(K_{1} I_{c}\right)}+\frac{K_{c}}{P L}$

$A_{I 2}=\frac{K_{v} K_{1} K_{2}}{P K_{1} \tan \left(K_{2} I_{v}\right)+K_{2} \tan \left(K_{1} I_{c}\right) \cos \left(K_{2} I_{v}\right) \cos \left(K_{1} I_{c}\right)}-\frac{K_{v}}{P L}$

$B_{1}=\frac{K_{1}}{Q}\left\{T_{1}\left[\frac{\left[K_{2}-K_{1} \tan \left(K_{1} I_{c}\right) \tan \left(K_{2} I_{v}\right)\right]}{\tan \left(K_{1} I_{c}\right) \tan \left(K_{2} I_{v}\right)}\right]-\frac{T_{2} K_{2}}{\sin \left(K_{1} I_{c}\right) \tan \left(K_{2} I_{v}\right)}-\frac{T_{3} K_{2}}{\sin \left(K_{1} I_{c}\right) \tan \left(K_{2} I_{v}\right)}\right.$

$\left.+\left(\beta+\frac{W}{P}\right) \frac{1}{\sin \left(K_{i} I_{c}\right)}-\frac{\left(e_{v}-e_{c}\right)}{L}+\frac{\left(f_{v}-f_{c}\right)}{L}-\frac{R_{c}}{P}\right\}$

$A_{21}=-\frac{K_{c}}{P}\left[\frac{\left[K_{1} K_{2}\right]}{\left[K_{1} \tan \left(K_{2} I_{v}\right)+K_{2} \tan \left(K_{1} I_{c}\right)\right]}\right] \frac{1}{\cos \left(K_{1} I_{c}\right) \cos \left(K_{2} I_{v}\right)}+\frac{K_{c}}{P L}$

$A_{22}=\left[1+\frac{K_{v}\left[K_{2} \tan \left(K_{1} I_{c}\right) \tan \left(K_{2} I_{c}\right)+K_{1}\right]}{P\left[K_{1} \tan \left(K_{2} I_{v}\right)+K_{2} \tan \left(K_{1} I_{c}\right)\right]}\right] \cdot \frac{K_{2} \cos \left(K_{2} I_{c}\right)}{\cos \left(K_{2} I_{v}\right) \cos \left(K_{2} L\right)}-\frac{K_{v} K_{2} \sin \left(K_{2} L\right)}{P \cos \left(K_{2} L\right)}-\frac{K_{v}}{P L}$

$B_{2}=\frac{K_{2}}{Q}\left\{\left[\frac{T_{1} K_{1}}{\sin \left(K_{1} I_{c}\right) \sin \left(K_{2} I_{v}\right)}\right]-T_{2}\left[\frac{\left(K_{2} \tan \left(K_{1} I_{c}\right)+\tan \left(K_{2} I_{c}\right)\right)+K_{1} \cos \left(K_{2} I_{c}\right)}{\tan \left(K_{1} I_{c}\right) \sin \left(K_{2} I_{v}\right) \cos \left(K_{2} L\right)}\right]\right.$

$\left.-\frac{T_{3} K_{1}}{\tan \left(K_{1} I_{c}\right) \sin \left(K_{2} I_{v}\right)}-\left(\beta+\frac{W}{P}\right) \frac{1}{\sin \left(K_{2} I_{v}\right)}+T_{2} K_{2} \tan \left(K_{2} L\right)-\frac{\left(e_{v}-e_{c}\right)}{L}+\frac{\left(f_{v}-f_{c}\right)}{L}-\frac{R_{v}}{P}\right\}$

Solving simultaneously the equations (21) y (22) oneobtains:

$\beta_{c}=\frac{B_{1} A_{22}-A_{12} B_{2}}{A_{11} A_{22}-A_{12} A_{21}}$

And

$\beta_{c}=\frac{B_{2} A_{11}-A_{21} B_{1}}{A_{11} A_{22}-A_{12} A_{21}}$

With the equations (10), (11), (17), (18), (29), and (30) one can determine the unknowns $C_{1}, C_{2}, D_{1}, D_{2} \beta_{c}$, and $\beta_{\mathrm{v}}$ respectively, in the equations of the displacement (6) and (7), and in the equations for the slope (14) and (15). The equation for the flexural moment for the tube part of the body is found using equations (12), and similarly the flexural moment in the rod part of the body is found using the equation:

$M_{2}=-\frac{P\left(e_{v}-e_{c}\right)}{L}(L-z)+\frac{P\left(f_{v}-f_{c}\right)}{L}(L-z)-\frac{\left[k_{c} \beta_{c}-k_{v} \beta_{v}\right]}{L}(L-z)+R_{v}(L-z)-P f_{v}-K_{v} \beta_{v}$

$-\frac{W_{2}}{2}(L-z)^{2}+P\left(e_{v}+y_{2}\right)$

\section{CONCLUSIONS.}

An approach has been presented for the static analysis of a hydraulic cylinder of a single stage. The approach is comprehensive, and permits consideration of a number of factors, which have not been accounted for in previous studies.

The equations obtained allow to improve the design of the hydraulic cylinders providing economical designs with appropriate safety factors. 


\section{REFERENCES.}

[1] G. Seebacher, H. Winkler, "Evaluating flexibility in discrete manufacturing based on performance and efficiency", Int. J. Production Economics, vol. 153, pp. 340-351, Jul. 2014.

[2] A. Trąbka, "Dynamics of telescopic cranes with flexible structural components",International Journal of Mechanical Sciences, vol. 88, pp. 162-174, Nov. 2014.

[3] B, Posiadala, D. Cekus, "Vibration model and analysis of three-member telescopic boom with hydraulic cylinder for its radius change",International Journal of Bifurcation and Chaos, vol. 21, pp. 2883-2892, Oct. 2011.

[4] C. H. Yoo, C. R. Siegel, "Column loadings on telescopic power cylinders",Computers \& structures, Vol. 22, No 3, pp. 245-251, Feb.2003.

[5] S. Baragetti, A. Terranova, "Bending behaviour of double-acting hydraulic actuator's". Proc. of the Institution of Mechanical Engineers, Part C: Journal of Mechanical Engineering Science, vol. 215 No 5, pp. 607-619, May. 2001.

[6] T. Nguyen, K. H. Tan, “Thermal-induced restraint forces in reinforced concrete columns subjected to eccentric loads". Fire Safety Journal, vol. 69, pp.136-146,Oct. 2014.

[7] M. R. Sheidaii, R. Bahraminejad, "Evaluation of compression member buckling and post-buckling behavior using artificial neural network".Journal of Constructional Steel Research, vol. 70, pp. 71-77. Mar. 2012.

[8] R. Mijailović, "Modelling the dynamic behaviour of the truck-crane",Journal Transport. vol. 26 No 4, pp. 410-417, Jan. 2012.

[9] N. Uchiyama,"Robust control of rotary crane by partial-state feedback with integrator",Mechatronics,vol. 19, pp.1294-1302,Dec. 2009.

[10] V. Gómez, J. Cabello, "Low carbon steel evaluation for oleohydraulic cylinders manufacturing". Mechanical Engineering, vol. 6, pp. 7-11, Jan. 2003.

[11] S.P. Timoshenko, "History of Strength of Materials", New York: Dover, 1983.

[12] W.P. Dawkins, S.K. Iyengar,"Stress analysis of hydraulic cylinders", in Proc.National Conference on Fluid Power, Chicago, vol. 29. 1975.

[13] S. Uzny, "Free vibrations and stability of hydraulic cylinder fixed elastically on both ends",inProc. Appl. Math. Mech, vol. 9, No. 1, pp. 303-304. Mar.2010.

[14] L. Tomski, S. Uzny, "A hydraulic cylinder subjected to Euler's load in aspect of the stability and free vibrations taking into account discrete elastic elements",Archives of civil and mechanical engineering, vol. 11, No 3, pp. 769-785, May. 2011.

[15] M. Torres del Toro,"Application of Differential Equations to the Analysis of the Stability of Telescopic Hydraulic Cylinders",M. Eng. thesis, University of Cienfuegos, Nov. 1999.

[16] O. Navarro, "Stability of Telescopic Hydraulic Cylinders", M. Eng. thesis, University of Cienfuegos, Sep. 2001.

[17] M. Balbis, R. Goytisolo, H. Hernández, J. Cabello,"Stress in butt welded joints of open profiles under torsion" Ingeniare, vol. 23, pp. 638-646, Nov. 2015.

[18] N. Kumar, M. Parvez, "Force distribution on telescopic boom of crane".Int. J. Mech. Eng. Robot. Res. vol.1, pp. 96-104,Jul. 2012.

[19] J. Cabello, "Methodology for the design of hydraulic cylinders". Construcción de maquinarias, vol. 1.No. 3,Nov. 1995.

[20] H.G. Puhl, "Static analysis and experimentation of elastic hydraulic cylinders", Forschungsheft, vol.34, No. 6, pp. 237-244.Jun.1973.

\section{AUTHOR PROFILE}

Victor Gómez Rodríguez is working as professor at Bolivarian Technological Institute of Technology. His interest areas are applied mechanics.

Juan Jose Cabello Eras is working as professor at Universidad de la Costa. His interest areas are applied mechanics and energy efficiency.

Hernan Hernández Herrera is working as professor at Universidad de la Costa. His interest areas are applied mechanics and energy efficiency.

Rafael Goytisolo Espinosa is working as professor at Universidad de Cienfuegos. His interest areas are applied mechanics. 